\title{
Best Practices for Integrating Medical Students Into Telehealth Visits
}

Maria Wamsley ${ }^{1}$, MD; Laeesha Cornejo ${ }^{2}$, BA; Irina Kryzhanovskaya ${ }^{1}, \mathrm{MD}$; Brian W Lin ${ }^{3,4}$, MD; Joseph Sullivan ${ }^{5}$, MD; Jordan Yoder ${ }^{1,6}, \mathrm{MD}$; Tali Ziv ${ }^{1,6}, \mathrm{MD}$

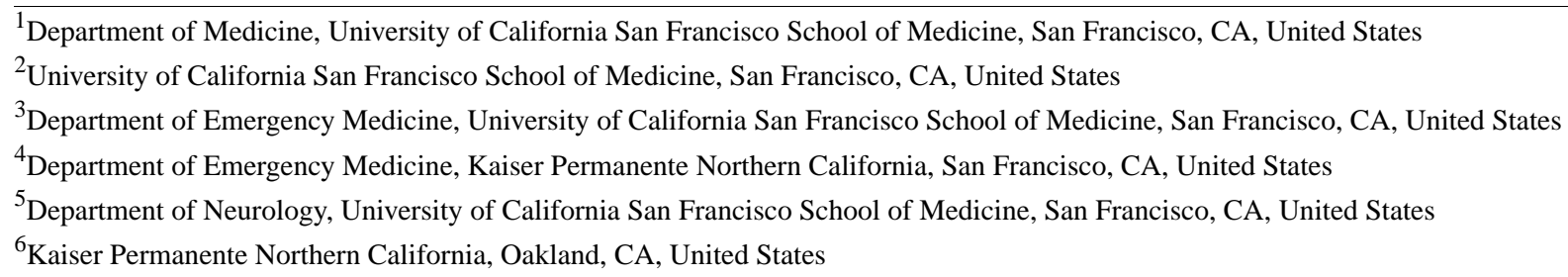

Corresponding Author:

Maria Wamsley, MD

Department of Medicine

University of California San Francisco School of Medicine

San Francisco, CA

United States

Phone: 14155148660

Email: maria.wamsley@ucsf.edu

\section{Abstract}

Telehealth has become an increasingly important part of health care delivery, with a dramatic rise in telehealth visits during the COVID-19 pandemic. Telehealth visits will continue to be a part of care delivery after the pandemic subsides, and it is important that medical students receive training in telehealth skills to meet emerging telehealth competencies. This paper describes strategies for successfully integrating medical students into telehealth visits in the ambulatory setting based on existing literature and the extensive experience of the authors teaching and learning in the telehealth environment.

(JMIR Med Educ 2021;7(2):e27877) doi: 10.2196/27877

\section{KEYWORDS}

telehealth; undergraduate medical education; workplace learning; ambulatory care; telehealth competencies; medical education; student education; digital learning; online learning; ambulatory; digital health

\section{Introduction}

Telehealth and telemedicine are terms that are used interchangeably in much of the existing literature and have become an increasingly important part of health care in the last several decades [1]. Telehealth or virtual visits are defined as live, synchronous, interactive encounters between a patient and a health care provider through video, telephone, or live chat [2]. The COVID-19 pandemic has greatly accelerated the use of telehealth visits to improve patient access to care and minimize risks to patients and health care providers [3,4], and even after the pandemic subsides, telehealth will remain an important and growing modality for care delivery [5]. The benefits of telehealth include increased access to care in remote or rural areas, mitigation of workforce shortages, improved chronic disease management, and improved health outcomes [6].
Given the rise in telehealth, it is important to prepare medical students for effective participation in telehealth visits and share best practices for integrating students into telehealth visits. The 2015-2016 Liaison Committee on Medical Education Annual Medical School Questionnaire reported that over a quarter of US medical schools have implemented telehealth training in their preclinical curriculum and nearly half have implemented it in their clinical curriculum [7]. However, much of the existing literature on telehealth for learners focuses on residents $[3,8,9]$ or telehealth curricular descriptions for medical students [7,10-13]. There is limited but growing literature on integrating medical students into telehealth visits [14-17].

Integrating students into telehealth visits has several potential advantages. It can overcome space limitations in clinical settings, provide opportunities for learners to participate in clinical care at a distance including in settings that may be less 
accessible (eg, international or rural settings), provide a window into patients' home environments, and allow students to participate in specialty consultations and interprofessional care. Telehealth provides teachers with opportunities both for direct observation of students' patient communication and physical examination skills and for teaching focused on clinical reasoning [18].

In this paper, we describe strategies for effectively integrating medical students into telehealth visits in the ambulatory setting. We derive our approach from the educational literature and from our extensive experience with direct recommendations for teachers who have integrated or wish to integrate learners into telehealth visits. We have organized our suggestions based on Billett's framework of workplace learning that highlights the importance of pedagogic practices before, during, and after practice-based experiences [19]. We do acknowledge that there is overlap between these categories; however, we feel that it is helpful for teachers to have a framework for approaching the incorporation of learners into telehealth experiences.

\section{Before the Visit}

\section{Know Your Telehealth Platform}

Facility with your telehealth platform is imperative to maximize time focused on teaching, observation, and learner assessment. Institutional decisions to use encrypted software packages approved for the transmission of protected health information leave health care providers working within the confines of systems and software packages that may be unfamiliar. Institutional training and online tutorials can enhance comfort and skills with specific technology platforms and increase familiarity with system features that may be disabled, enabled, or customized. To build patient trust and facilitate the teaching experience with the learner, it is critical that the teacher is comfortable with the telehealth platform and can troubleshoot challenges in advance of any telehealth visit.

\section{Provide Students With a Telehealth Curriculum That Is Aligned With Telehealth Competencies}

The literature describes various telehealth curricula for medical students $[7,10,11,13]$ and residents [3,8,9,20-22]. There has been an attempt to define both general [23] and discipline-specific telehealth competencies at the postgraduate level [8]. The American Association of Medical Colleges recently released telehealth competencies for the recent medical school graduate entering residency, the graduating resident entering practice, and the experienced practicing physician [24]. It is important to note that teachers may not yet have mastered telehealth competencies given the evolving nature of these competencies and the relatively recent expansion of telehealth.

Based on the available literature, telehealth curricula should include the following key content areas: technical skills needed to operate equipment and software, including troubleshooting difficulties; professionalism in telehealth, including review of informed consent and patient privacy; telehealth communication skills [25-27]; physical examination skills in the telehealth environment [28,29]; and affordances and limitations of telehealth visits, including the potential for telehealth to increase disparities in care [30]. It is important to specifically teach and coach students through sensitive aspects of patient history, which can include eliciting social and mental health histories and intimate partner violence screening [31] and which may be more challenging in the virtual environment. Strategies such as ensuring safety and privacy prior to initiating a telehealth visit by asking simple yes-or-no questions can be taught and modeled for learners, who in turn can be provided with opportunities to practice these skills through roleplay or simulation. Described methods for delivery of telehealth curricula include e-learning, lectures, and small group discussions. In addition, it is essential to provide opportunities for telehealth skills practice with feedback, which can be accomplished using objective structured clinical examinations in a simulated telehealth environment or in the context of patient care [8,10,32].

\section{Prepare Students for Success in the Virtual Visit}

The first step to student success in a virtual visit is ensuring access to the appropriate technology and a private space in which to successfully conduct a telehealth visit. There may be disparities in student access to reliable broadband service, and many students may live in shared living spaces without adequate access to the private space needed for a telehealth visit. Medical schools can address these disparities by providing private rooms with Wi-Fi access for students to conduct telehealth visits or through providing Wi-Fi hotspots for learners without access to reliable broadband service.

To contribute to the team and learn most effectively, students require orientation and goal setting at the start of each telehealth session. As Knowles' theory of andragogy outlines, adult learners are self-directed and learn best when engaged in the workplace with authentic roles [33]. In addition, learners involved in formulating task strategies perform better with a higher self-efficacy than those who do not participate in formulating strategies [34]. Establishing a sense of the student's level of medical knowledge and any other core skills required as well as considering the student's prior experience with telehealth will prepare for a more productive session. Choose patients together from the schedule with the highest learning potential and match the patients' demographics, chief complaints, problem list, and presentation complexity with the student's learning goals for the session. Share with the student your history of caring for the patient and any tips or pearls from previous encounters that will help the student. For example, if you know the patient tends to prefer a certain approach, this is helpful to share with the student in advance. Prime the student for success by starting with easier initial tasks. Be specific with expectations by, for example, delineating the amount of time the student should spend on the visit before looping you in again, what tasks the student should accomplish, and how to best communicate with you during the visit.

\section{Leverage Students' Knowledge of Technology}

Ramping up to provide virtual care is challenging and may be more difficult for those clinicians who are accustomed to a particular structure and rhythm of in-person clinical visits. In contrast, students are still developing their frameworks for the clinical visit and may be more flexible in their approach. Learners may appreciate the early integration of technology in 
their learning [35], recognizing the significant role that telehealth will play in future outpatient care delivery. Millennials, defined as those individuals born between 1981 and 2000, currently constitute the majority of medical students. They have been shaped by a profound expansion of information technology, and their facility with various hardware, platforms, and apps can be time-saving in the telehealth work environment. Millennial learners embrace collaboration, and they thrive in flat rather than pyramidal structures [36]. Inviting a student to share with the team what they know about how to best use technology in the context of telehealth visits will strengthen the learning climate and invite collaborative learning. As Generation $\mathrm{Z}$ students (those born between 1997 and 2012) soon emerge among our trainees, an even more technology-focused generation will challenge us to once again rethink our relationship to technology and the ways educational practice in telehealth will necessarily evolve.

\section{Address Disparities in Telehealth Utilization}

Although the use of telehealth visits has increased dramatically, this trend has been disproportionately generated by young, non-Hispanic White patients. Patients over 65 years, those whose primary language is not English, and those insured by Medicare or Medicaid all saw a decrease in health care utilization when practices shifted from in-person to virtual care in the context of the COVID-19 pandemic [30]. As medical training and health care delivery become more virtual, medical students will have an increasingly important role in addressing disparities in access to health care. Teachers can encourage their students to engage in local efforts to improve broadband and mobile device access in underserved communities and to challenge health system barriers to telehealth access. Support for this work can be provided through systems-improvement projects or elective courses. For example, students can reach out to those most in need of connection, such as more frail older adults, screen them for mood disorders, and connect them with community resources. In the clinical setting, teachers should prompt students to proactively reach out to patients whose primary language is not English to check if they need assistance accessing virtual care by ensuring adequate access to interpreters in the visit, screening patients for privacy or technical barriers, and teaching patients how to use the telehealth platform before the appointment begins. Addressing disparities in telehealth access is also crucial for learner development. Medical trainees' preparedness to deliver cross-cultural care often trails other clinical milestones [37], but exposure to and discussion of health care disparities in medical school has been linked to improvements in that preparedness [38]. Development of formal curricula to adapt cultural humility and antiracism training for virtual care and role modeling these within the virtual workplace will both be imperative in this new era of medical education.

\section{During the Visit}

\section{Establish and Model "Webside Manner"}

Connection means more than just establishing a video or telephone connection between you, the patient, and the student. Most in-person visits to a medical provider involve some physical interaction, such as a handshake or other nonverbal interaction. Virtual visits have changed that dynamic, requiring new strategies for "webside manner" to establish this extremely important personal connection. To address these challenges in communication and opportunities for relationship building, the authors of the Stanford Presence 5 [26] adapted their original evidence-based practices to help clinicians foster humanism during clinical encounters for telehealth visits [26]. Body positioning, eye contact, nodding, smiling to demonstrate a listening posture, and allowing extra pauses before speaking to account for lag time are particularly important when engaging in a telehealth visit, especially with three or more participants (patient, teacher, and student) [39]. To allow for optimal visualization of body language, position the camera in a way that allows others to see your torso and arms and use gestures as you would in person but keep the gestures in the square of your body (ie, closer to your shoulder). Be mindful that gestures may appear more unnatural with virtual backgrounds. Although it is natural to look at participants' faces and video on the screen, from the perspective of the student or patient, this does not come across as direct eye contact. Try to maintain direct eye contact by looking at the camera when you are speaking. Consider putting something next to the camera lens that will remind you to focus your gaze there and close other computer windows to minimize distractions.

\section{Adapt the Students' Authentic Roles To Be Commensurate With Their Clinical Developmental Stage}

To establish an inviting virtual learning climate, you can start to iteratively develop the student's telehealth skills. Telehealth provides a rich opportunity for the student to join the greater community of practice [40], as they quickly learn competencies ranging from medical knowledge to systems-based practice. Consider the gradient of competency in the many domains within telehealth just as you would a continuum of competency in medical knowledge. Eventually the student might participate in all aspects of telehealth, including preparing for the session with appropriate technology in place, precharting, obtaining a history, completing a virtual physical exam, and providing patient education with anticipatory guidance. However, these steps might be considered building blocks and can be approached stepwise with supported participation matching the student's skill development [41]. Initially, students might listen in by telephone or video with the teacher and patient. As familiarity with the basic technical tools required to conduct a visit grows, the student can engage in independent communication with the patient for a portion of the encounter. One helpful framework to consider the student's skills and developmental progress is the Reporter, Interpreter, Manager, Educator framework [42], which describes the progression of student skills during the clinical clerkship year. For students in the reporter stage, eliciting an initial history in the telehealth visit might be an appropriate task, while students in the manager stage might be able to wrap up the visit with the patient, communicating the plan and next steps with faculty supervision. These expectations should be discussed with the learner as part of the previsit preparation. Students may also follow up on results of laboratory examinations and studies after the encounter. Frequent feedback and flexibility [43] to gauge 
competency while cultivating a growth mindset will allow the student to progress across multiple competencies.

\section{Ensure "Sidelines Communication"}

It is worth recognizing that when students and teachers work together in person, they have frequent points of contact. It is therefore important during telehealth sessions to preserve and promote opportunities for the student and teacher to communicate throughout the session. Dialogue is an important tool for building trust between students and teachers and can shift the power dynamic to provide students with a sense of expertise and autonomy [44]. The day-to-day interactions between students and teachers give teachers the opportunity to shape and understand the identity and roles of the medical students and provide students the dynamic to develop their professional identity [45]. It is therefore not surprising that medical students highly value having teachers who are readily available [44]. Agree on a private and reliable messaging platform for "sidelines communication" during the clinic session to communicate about timing, address questions, or provide support. Options include secure text messaging, computer communication platforms, phone calls, and videoconferencing chat functions. Which sidelines communication method you choose should be dictated by institutional privacy guidelines to comply with regulations such as the HIPAA (Health Insurance Portability and Accountability Act), institutional technical fire walls, and personal preference. Regardless of which sidelines communication you use, establishing a clear communication workflow allows students greater independence and teachers more efficient use of time while maintaining appropriate supervision.

\section{Foster Relationships: Engage the Patient and the Student Within the Virtual Environment}

Telehealth visits provide both additional challenges and opportunities for provider-patient communication and relationship building between the student, teacher, and patient. When reflecting on telehealth visits, patients report difficulty finding opportunities to speak, a sense that providers pay less attention to them, and an inability to establish a connection with their provider [46]. However, telehealth visits also present an opportunity to engage with patients in their own environments. At the beginning of the telehealth visit, extra consideration should be given to student introductions and consent, as creating a connection can be more difficult virtually. Best practices for in-person interactions, such as exploration of emotional cues, use of open-ended questions, and the teach-back method [47], should be adapted, modeled, and encouraged during virtual interactions. Similarly, relationship-centered care can also still be achieved through telehealth visits [48]. After first ensuring safety, privacy, and appropriate occasion, engaging in the patient, student, or provider's home environments can allow for a greater connection. Family members previously unable to attend office appointments can be involved, while pets or other important facets of patients' lives can add depth to the interaction. Lastly, be aware of virtual meeting fatigue that results from not having full access to nonverbal cues and the mental fatigue that results from having to process the accumulation of these important missing elements of in-person social interaction [49]. Engaging in relationship building and focusing on mindful communication can help prevent burnout within more virtual clinical and teaching environments [50].

\section{Build In Opportunities To Teach and Observe the Virtual Physical Exam}

Eliciting student learning goals in advance of the session will provide you with a focus for your teaching and observation. If the student identifies questions about how to perform an exam maneuver in your previsit conversation, take time to consider together how to most effectively perform the exam during the encounter. Even the more challenging maneuvers can be conducted over video or telephone. Plan in advance which specific examination maneuvers the student will perform and how to communicate the instructions for the exam to the patient. Consider with the student what can be gleaned from the encounter: how the patient tells their story; aspects of the history that help build the differential diagnosis; which data are available from wearable devices; or what findings can result from the "Telehealth Ten," a patient-assisted clinical examination to help guide providers in their physical examination and clinical reasoning over telemedicine [28]. Clerkship students have noted that they appreciate timely feedback during the telehealth encounter or right after the visit, and virtual exam skills observation allows for a focused discussion around behaviors the student can keep, start, or stop doing [14]. During the visit, it may become clear that the symptoms discussed or signs noted in the virtual examination require transition to an in-person visit. Preparing the student for this possibility by explicitly exploring it with the student in advance and discussing what options exist for transitioning patients to in-person visits will allow the student to consider the opportunities and limitations of the telehealth encounter. Additionally, modeling for the student how to approach this conversation with the patient provides another opportunity for student learning.

\section{After the Visit}

\section{Ensure a Post-Session Huddle: Set Aside Time To Debrief and Give Feedback}

As the closing guidepost on the telehealth journey with the student, a postsession huddle creates the opportunity to reflect on the visit, share feedback with the student based on their identified goals, and create a plan or a Specific, Measurable, Attainable, Realistic, and Time-Bound (SMART) goal [51] for the next telehealth visit and the time between visits. Whether you are working with a student for two sessions or twenty-two sessions, providing feedback in the moment based on your observations can help to stimulate the student's growth mindset and enhance the telehealth learning experience [52]. Having a feedback dialogue in a postsession online huddle without the patient present allows the teacher to share reinforcing and redirecting feedback based on their observations [14]. One potential structure for the postsession huddle is the "ask-tell-ask framework" [53]. First, ask the student to reflect on their own performance and then share (tell) your specific observations and feedback on the student's performance and developing telehealth skills. You can share your screen in the virtual 
platform to highlight any particular observations. After sharing your thoughts, ask the student for their reaction to your feedback. Close the postsession huddle with a request to the student to generate a SMART goal or a plan about how to continue progressing in their telehealth skills development. Students may share their SMART goal via electronic messaging or through a shared platform for tracking student goals and progress.

\section{Engage in Virtual Care Across Specialties}

When patients are seen by other health care providers, either in a different specialty or profession, it is often difficult for students to participate in-person if these appointments occur in different locations. Telehealth provides an opportunity for students to more readily join visits across departments with health care providers of diverse specialties and professions, enhancing opportunities for building longitudinal relationships with patients. Through active participation in patient care in different settings, the student can bridge health care providers across specialties and benefit from experiential learning, constructing knowledge and meaning from an authentic experience [41]. Encourage the student to solicit patient and provider permission in advance of joining a visit virtually. Students can provide additional support, navigation, education, and advocacy for patients during virtual visits in different settings [54]. With knowledge of the patient's history and diagnoses, students can share additional background and context for the health care provider. Encourage students to check for patient understanding before, during, and after the visit, as this is particularly important in helping the patient navigate multiple settings and ensuring that the patient and family members have an understanding of the impression and plan from every visit; furthermore, it provides the student with a better perspective of the patient's care experience.

\section{Conclusions}

It is clear that telehealth visits will continue to be an expanding modality for the provision of care in the future. Consequently, medical students will need to be trained to meet telehealth competencies, and teachers will need to be able to coach medical students in these important skills. Creating opportunities for students to engage in telehealth visits using the above outlined best practices will provide them with opportunities to practice telehealth skills safely and effectively with guidance and feedback from prepared teachers.

\section{Acknowledgments}

The authors would like to thank Mr Quincy D McCrary for his assistance with the preparation of the manuscript for publication.

\section{Conflicts of Interest}

None declared.

\section{References}

1. Tuckson RV, Edmunds M, Hodgkins ML. Telehealth. N Engl J Med 2017 Oct 19;377(16):1585-1592. [doi: 10.1056/NEJMsr1503323] [Medline: 29045204]

2. Telehealth: defining 21st century care. American Telemedicine Association. 2020. URL: https://www.americantelemed.org/ resource/why-telemedicine/ [accessed 2021-04-05]

3. Zha AM, Chung LS, Song SS, Majersik JJ, Jagolino-Cole AL. Training in neurology: adoption of resident teleneurology training in the wake of COVID-19: telemedicine crash course. Neurology 2020 Sep 01;95(9):404-407. [doi:

10.1212/WNL.0000000000010029] [Medline: 32554768]

4. Hollander JE, Carr BG. Virtually Perfect? Telemedicine for Covid-19. N Engl J Med 2020 Apr 30;382(18):1679-1681. [doi: 10.1056/NEJMp2003539] [Medline: 32160451]

5. Bashshur R, Doarn CR, Frenk JM, Kvedar JC, Woolliscroft JO. Telemedicine and the COVID-19 Pandemic, Lessons for the Future. Telemed J E Health 2020 May;26(5):571-573. [doi: 10.1089/tmj.2020.29040.rb] [Medline: 32275485]

6. Totten A, Womack D, Eden K, McDonagh M, Griffin J, Grusing S. Telehealth: mapping the evidence for patient outcomes from systematic reviews. AHRQ Comparative Effectiveness Technical Briefs 2016 Jun:13-44. [Medline: 27536752]

7. Waseh S, Dicker AP. Telemedicine training in undergraduate medical education: mixed-methods review. JMIR Med Educ 2019 Apr 08;5(1):e12515 [FREE Full text] [doi: 10.2196/12515] [Medline: $\underline{30958269}$ ]

8. Crawford A, Sunderji N, López J, Soklaridis S. Defining competencies for the practice of telepsychiatry through an assessment of resident learning needs. BMC Med Educ 2016 Jan 26;16:28 [FREE Full text] [doi: 10.1186/s12909-016-0529-0] [Medline: 26813286]

9. Govindarajan R, Anderson ER, Hesselbrock RR, Madhavan R, Moo LR, Mowzoon N, et al. Developing an outline for teleneurology curriculum: AAN Telemedicine Work Group recommendations. Neurology 2017 Aug 29;89(9):951-959. [doi: 10.1212/WNL.0000000000004285] [Medline: 28768842]

10. Jonas CE, Durning SJ, Zebrowski C, Cimino F. An interdisciplinary, multi-institution telehealth course for third-year medical students. Acad Med 2019 Jun;94(6):833-837. [doi: 10.1097/ACM.0000000000002701] [Medline: 30870152]

11. Edirippulige S, Armfield NR. Education and training to support the use of clinical telehealth: a review of the literature. $J$ Telemed Telecare 2017 Feb;23(2):273-282. [doi: 10.1177/1357633X16632968] [Medline: 26892005] 
12. Poncette A, Glauert DL, Mosch L, Braune K, Balzer F, Back D. Undergraduate medical competencies in digital health and curricular module development: mixed methods study. J Med Internet Res 2020 Oct 29;22(10):e22161 [FREE Full text] [doi: 10.2196/22161] [Medline: 33118935]

13. Rienits H, Teuss G, Bonney A. Teaching telehealth consultation skills. Clin Teach 2016 Apr;13(2):119-123. [doi: 10.1111/tct.12378] [Medline: 26016733]

14. Abraham HN, Opara IN, Dwaihy RL, Acuff C, Brauer B, Nabaty R, et al. Engaging third-year medical students on their internal medicine clerkship in telehealth during COVID-19. Cureus 2020 Jun 24;12(6):e8791 [FREE Full text] [doi: 10.7759/cureus.8791] [Medline: 32724740 ]

15. Chao TN, Frost AS, Brody RM, Byrnes YM, Cannady SB, Luu NN, et al. Creation of an interactive virtual surgical rotation for undergraduate medical education during the COVID-19 pandemic. J Surg Educ 2021;78(1):346-350 [FREE Full text] [doi: 10.1016/j.jsurg.2020.06.039] [Medline: 32654999]

16. Aron JA, Bulteel AJB, Clayman KA, Cornett JA, Filtz K, Heneghan L, et al. A role for telemedicine in medical education during the COVID-19 pandemic. Acad Med 2020 Nov;95(11):e4-e5 [FREE Full text] [doi: 10.1097/ACM.0000000000003572] [Medline: 32639263]

17. Cain R, Shafer Klink D, Yunus S. Telemedicine implementation in family medicine: undergraduate clerkship during COVID-19 pandemic. Med Educ 2020 Nov;54(11):1064-1065 [FREE Full text] [doi: 10.1111/medu.14313] [Medline: $\underline{32959423}$

18. Iancu AM, Kemp MT, Alam HB. Unmuting medical students' education: utilizing telemedicine during the COVID-19 pandemic and beyond. J Med Internet Res 2020 Jul 20;22(7):e19667 [FREE Full text] [doi: 10.2196/19667] [Medline: 32614776]

19. Billet S. Guidelines for practice: integrating practice-based experiences. Australian Learning \& Teaching Council.: Australian Learning \& Teaching Council; 2011. URL: https://stephenbillett.com.au/wp-content/uploads/2020/09/

Guidelines-for-practice-Integrating-practice-based-experiences.pdf [accessed 2021-04-05]

20. Afshari M, Witek NP, Galifianakis NB. Education Research: An experiential outpatient teleneurology curriculum for residents. Neurology 2019 Jul 23;93(4):170-175. [doi: 10.1212/WNL.0000000000007848] [Medline: 31332085]

21. Kirkland EB, DuBose-Morris R, Duckett A. Telehealth for the internal medicine resident: A 3-year longitudinal curriculum. J Telemed Telecare 2019 Dec 31:1357633X19896683. [doi: 10.1177/1357633X19896683] [Medline: $\underline{31888396}$ ]

22. Hilty D, Chan S, Torous J, Luo J, Boland R. A framework for competencies for the use of mobile technologies in psychiatry and medicine: scoping review. JMIR Mhealth Uhealth 2020 Feb 21;8(2):e12229 [FREE Full text] [doi: 10.2196/12229] [Medline: 32130153]

23. Sharma R, Nachum S, Davidson KW, Nochomovitz M. It's not just FaceTime: core competencies for the medical virtualist. Int J Emerg Med 2019 Mar 12;12(1):8 [FREE Full text] [doi: 10.1186/s12245-019-0226-y] [Medline: $\underline{31179921]}$

24. Association of American Medical Colleges. Telehealth competencies across the learning continuum. Washington DC: AAMC; 2021. URL: https://store.aamc.org/telehealth-competencies-across-the-learning-continuum.html [accessed 2021-04-04]

25. Shankar M, Fischer M, Brown-Johnson C, Safaeinili N, Haverfield M, Shaw J. Humanism in telemedicine: connecting through virtual visits during the COVID-19 pandemic. Annals of Family Medicine Preprint Collections 2020 Apr 13:1-10 [FREE Full text]

26. Zulman DM, Haverfield MC, Shaw JG, Brown-Johnson CG, Schwartz R, Tierney AA, et al. Telepresence 5: A ritual of connection for virtual visits. 2021. URL: https://med.stanford.edu/presence/initiatives/stanford-presence-5/tele-presence-5. $\underline{\mathrm{html}}$ [accessed 2021-04-05]

27. Telehealth communication: quick tips. Academy of Communication in Healthcare. 2021. URL: http://achonline.org/ Telehealth [accessed 2021-04-05]

28. Benziger CP, Huffman MD, Sweis RN, Stone NJ. The telehealth ten: a guide for a patient-assisted virtual physical examination. Am J Med 2021 Jan;134(1):48-51 [FREE Full text] [doi: 10.1016/j.amjmed.2020.06.015] [Medline: 32687813]

29. Ansary AM, Martinez JN, Scott JD. The virtual physical exam in the 21 st century. J Telemed Telecare 2019 Nov 06:1357633X19878330. [doi: 10.1177/1357633X19878330] [Medline: 31690169]

30. Nouri S, Khoong EC, Lyles CR, Karliner L. Addressing equity in telemedicine for chronic disease management during the covid-19 pandemic. NEJM Catalyst Innovations in Care Delivery 2020;1(3):1-13 [FREE Full text] [doi: 10.1056/CAT.20.0123]

31. Rossi FS, Shankar M, Buckholdt K, Bailey Y, Israni ST, Iverson KM. Trying times and trying out solutions: intimate partner violence screening and support for women veterans during COVID-19. J Gen Intern Med 2020 Sep;35(9):2728-2731 [FREE Full text] [doi: 10.1007/s11606-020-05990-0] [Medline: 32607932]

32. Cantone RE, Palmer R, Dodson LG, Biagioli FE. Insomnia Telemedicine OSCE (TeleOSCE): a simulated standardized patient video-visit case for clerkship students. MedEdPORTAL 2019 Dec 27;15:10867 [FREE Full text] [doi: 10.15766/mep 2374-8265.10867] [Medline: $\underline{\text { 32051850] }}$

33. Knowles M. Andragogy in Action: Applying Modern Principles of Adult Learning 1st edition. San Francisco: Jossey-Bass; 1984. 
34. Locke EA, Alavi M, Wagner III J. Participation in decision making: An information exchange perspective. In: Ferris GR, editor. Research in personnel and human resources management: Elsevier Science/JAI Press; 1997:293-331.

35. Paul N, Kohara S, Khera GK, Gunawardena R. Integration of technology in medical education on primary care during the COVID-19 pandemic: students' viewpoint. JMIR Med Educ 2020 Nov 18;6(2):e22926 [FREE Full text] [doi: 10.2196/22926] [Medline: $\underline{33112760]}$

36. Waljee JF, Chopra V, Saint S. Mentoring millennials. JAMA 2020 May 05;323(17):1716-1717. [doi: 10.1001/jama.2020.3085] [Medline: 32369152]

37. Weissman JS, Betancourt J, Campbell EG, Park ER, Kim M, Clarridge B, et al. Resident physicians' preparedness to provide cross-cultural care. JAMA 2005 Sep 07;294(9):1058-1067. [doi: 10.1001/jama.294.9.1058] [Medline: 16145026 ]

38. van Ryn M, Hardeman R, Phelan SM, Burgess DJ, Dovidio JF, Herrin J, et al. Medical school experiences associated with change in implicit racial bias among 3547 students: a medical student changes study report. J Gen Intern Med 2015 Dec;30(12):1748-1756 [FREE Full text] [doi: 10.1007/s11606-015-3447-7] [Medline: 26129779]

39. Adams RD. Virtual meeting 101: body language tips for Zoom, Teams, and life. Tech Republic. 2020 Jul 10. URL: https:/ /www.techrepublic.com/article/virtual-meeting-101-body-language-tips-for-zoom-teams-and-life/ [accessed 2021-04-12]

40. Wenger E. Communities of practice and social learning systems: the career of a concept. In: Blackmore C, editor. Social Learning Systems and Communities of Practice. London: Springer London; 2010:179-198.

41. Dornan T, Boshuizen H, King N, Scherpbier A. Experience-based learning: a model linking the processes and outcomes of medical students' workplace learning. Med Educ 2007 Jan;41(1):84-91. [doi: 10.1111/j.1365-2929.2006.02652.x] [Medline: 17209896$]$

42. Pangaro L. A new vocabulary and other innovations for improving descriptive in-training evaluations. Acad Med 1999 Nov;74(11):1203-1207. [doi: 10.1097/00001888-199911000-00012] [Medline: 10587681$]$

43. Hauer KE, Lockspeiser TM, Chen HC. The COVID-19 pandemic as an imperative to advance medical student assessment: three areas for change. Acad Med 2021 Feb 01;96(2):182-185 [FREE Full text] [doi: 10.1097/ACM.0000000000003764] [Medline: 33003038]

44. Hendren EM, Kumagai AK. A matter of trust. Acad Med 2019 Sep;94(9):1270-1272. [doi: 10.1097/ACM.0000000000002846] [Medline: $\underline{\text { 31460913] }}$

45. van der Zwet J, Dornan T, Teunissen PW, de Jonge LPJWM, Scherpbier AJJA. Making sense of how physician preceptors interact with medical students: discourses of dialogue, good medical practice, and relationship trajectories. Adv Health Sci Educ Theory Pract 2014 Mar;19(1):85-98. [doi: 10.1007/s10459-013-9465-5] [Medline: 23771397]

46. Gordon HS, Solanki P, Bokhour BG, Gopal RK. "I'm not feeling like I'm part of the conversation" patients' perspectives on communicating in clinical video telehealth visits. J Gen Intern Med 2020 Jun;35(6):1751-1758. [doi: 10.1007/s11606-020-05673-w] [Medline: 32016705]

47. Bodenheimer T. Teach-back: a simple technique to enhance patients' understanding. Fam Pract Manag 2018;25(4):20-22 [FREE Full text] [Medline: 29989780]

48. Beach MC, Inui T, Relationship-Centered CRN. Relationship-centered care. A constructive reframing. J Gen Intern Med 2006 Jan;21 Suppl 1:S3-S8 [FREE Full text] [doi: 10.1111/j.1525-1497.2006.00302.x] [Medline: 16405707]

49. Blank $\mathrm{S}$. What's missing from zoom reminds us what it means to be human. Medium. 2020. URL: https://medium.com/ @ sgblank/whats-missing-from-zoom-reminds-us-what-it-means-to-be-human-651be7cbff39 [accessed 2021-04-12]

50. Krasner MS, Epstein RM, Beckman H, Suchman AL, Chapman B, Mooney CJ, et al. Association of an educational program in mindful communication with burnout, empathy, and attitudes among primary care physicians. JAMA 2009 Sep 23;302(12):1284-1293. [doi: 10.1001/jama.2009.1384] [Medline: 19773563]

51. O'Neill J, Conzemius AE. The Power of SMART Goals: Using Goals to Improve Student Learning. Bloomington: Solution Tree; 2006.

52. Ramani S, Könings KD, Ginsburg S, van der Vleuten CPM. Twelve tips to promote a feedback culture with a growth mind-set: swinging the feedback pendulum from recipes to relationships. Med Teach 2019 Jun;41(6):625-631. [doi: 10.1080/0142159X.2018.1432850] [Medline: 29411668]

53. French JC, Colbert CY, Pien LC, Dannefer EF, Taylor CA. Targeted feedback in the milestones era: utilization of the ask-tell-ask feedback model to promote reflection and self-assessment. Journal of Surgical Education 2015 Nov;72(6):e274-e279. [doi: 10.1016/j.jsurg.2015.05.016]

54. Poncelet AN, Wamsley M, Hauer KE, Lai C, Becker T, O'Brien B. Patient views of continuity relationships with medical students. Med Teach 2013 Jun;35(6):465-471. [doi: 10.3109/0142159X.2013.774335] [Medline: 23477473]

\section{Abbreviations}

HIPAA: Health Insurance Portability and Accountability Act

SMART: Specific, Measurable, Attainable, Realistic, and Time-Bound 
Edited by $G$ Eysenbach; submitted 10.02.21; peer-reviewed by D Newman, $Y$ Lin; comments to author 11.03.21; revised version received 17.03.21; accepted 25.03.21; published 21.04.21

Please cite as:

Wamsley M, Cornejo L, Kryzhanovskaya I, Lin BW, Sullivan J, Yoder J, Ziv T

Best Practices for Integrating Medical Students Into Telehealth Visits

JMIR Med Educ 2021;7(2):e27877

URL: https://mededu.jmir.org/2021/2/e27877

doi: $10.2196 / 27877$

PMID:

CMaria Wamsley, Laeesha Cornejo, Irina Kryzhanovskaya, Brian W Lin, Joseph Sullivan, Jordan Yoder, Tali Ziv. Originally published in JMIR Medical Education (https://mededu.jmir.org), 21.04.2021. This is an open-access article distributed under the terms of the Creative Commons Attribution License (https://creativecommons.org/licenses/by/4.0/), which permits unrestricted use, distribution, and reproduction in any medium, provided the original work, first published in JMIR Medical Education, is properly cited. The complete bibliographic information, a link to the original publication on http://mededu.jmir.org/, as well as this copyright and license information must be included. 